\title{
Ab Initio Molecular Dynamics Simulations to Interpret the Molecular Fragmentation Induced in Deoxyribose by Synchrotron Soft X-Rays
}

\author{
Marie-Anne Hervé du Penhoat ${ }^{1, *(\mathbb{D})}$, Anis Hamila ${ }^{1}$, Marie-Pierre Gaigeot ${ }^{2}{ }^{\mathbb{D}}$, \\ Rodolphe Vuilleumier ${ }^{3}{ }^{(1)}$, Kentaro Fujii ${ }^{4}$, Akinari Yokoya ${ }^{4}$ and Marie-Françoise Politis ${ }^{2}$ \\ 1 IMPMC, Sorbonne Université, UMR CNRS 7590, MNHN, 75005 Paris, France; anis_hamila@hotmail.fr \\ 2 LAMBE UMR8587, Université d'Evry val d'Essonne, CNRS, CEA, Université Paris-Saclay, \\ 91025 Evry, France; mgaigeot@univ-evry.fr (M.-P.G.); mfpolitis@gmail.com (M.-F.P.) \\ 3 PASTEUR, Département de Chimie, École Normale Supérieure, PSL University, Sorbonne Université, CNRS, \\ 75005 Paris, France; rodolphe.vuilleumier@ens.fr \\ 4 National Institutes for Quantum and Radiological Science and Technology, 319-1106 Tokai, Japan; \\ fujii.kentaro@qst.go.jp (K.F.); yokoya.akinari@qst.go.jp (A.Y.) \\ * Correspondence: marie-anne.herve_du_penhoat@upmc.fr; Tel.: +33-1-44-27-72-05
}

Received: 21 October 2019; Accepted: 4 December 2019; Published: 10 December 2019

\begin{abstract}
It has been suggested that core ionization in DNA atoms could induce complex, irreparable damage. Synchrotron soft X-rays have been used to probe the damage induced by such events in thin films of DNA components. In a complementary approach, we investigate the fragmentation dynamics following a carbon or oxygen K-shell ionization in 2-deoxy-D-ribose (DR), a major component in the DNA chain. Core ionization of the sugars hydration layer is also studied. To that aim, we use state-of-the-art ab initio Density Functional Theory-based Molecular Dynamics (MD) simulations. The ultrafast dissociation dynamics of the core ionized molecule, prior Auger decay, is modeled for about $10 \mathrm{fs}$. We show that the core-ionization of oxygen atoms within DR or its hydration layer may induce proton transfers towards nearby molecules, before Auger decay. In a second step, we model an Auger effect occurring either at the beginning or at the end of the core-hole dynamics. Two electrons are removed from the deepest valence molecular orbitals localized on the initially core-ionized oxygen atom $\left(\mathrm{O}^{*}\right)$, and this electronic state is propagated by means of Ehrenfest MD. We show an ultrafast dissociation of the $\mathrm{DR}^{2+}$ molecule C-O* bonds, which, in most cases, seems independent of the time at which Auger decay occurs.
\end{abstract}

Keywords: DNA; ionization; dissociation

\section{Introduction}

Ionizing radiations, such as hard X-rays, high-energy electrons, or swift ions, are used in cancer therapies to kill malignant cells. It has been suggested that inner-shell ionization in DNA constituent atoms could be partly responsible for cell death upon irradiation with heavy ions [1] or $\gamma$-rays [2]. Inner-shell ionizations are indeed particularly violent events. After a predissociation phase of a few femtoseconds, core holes in light atoms, such as carbon and oxygen, deexcite by ejecting an Auger electron with nearly $100 \%$ probability. Core ionization thus leads to the double ionization of the molecule and to the emission of two few hundred electronvolts electrons. In the sub-keV energy range, electrons have inelastic mean free paths of a few nanometers [3], and may thus induce clusters of ionizations in the vicinity of the core-ionized molecule. If taking place in DNA, or its hydration layer, inner-shell ionizations are thus expected to induce complex, irreparable, DNA damage [4]. 
DNA complex damage is critical for the cell because it can lead to important biological consequences such as chromosome aberrations, cell death, and cell conversion to malignancy [5-8].

Soft X-rays (0.1-5 keV) are particularly well adapted to investigate such events as they mainly interact through the removal of K-shell electrons as long as the photons energy is above the atoms $\mathrm{K}$-shell binding energy (284 and $543 \mathrm{eV}$, for carbon and oxygen, respectively [9]). Soft X-rays are however poorly penetrating radiations, so that condensed phase experiments remain a challenge. Different setups have been designed to irradiate biological samples either with X-ray tubes [10] or at synchroton facilities (for a review see [11]). The latter offer the advantage that any photon energy may be selected, thus allowing to compare biological effects upon irradiation with photons below and above a particular K-edge. Various biological endpoints have been investigated, such as cellular inactivation, chromosome aberration, and damage to plasmid or cellular DNA (for a review see [11]).

Such studies provide an integrated response of the biological system to the initial core ionization event. Investigating specifically the molecular damage originating from a core ionization is however complicated in the condensed phase, because the photo- and Auger electrons induce many additional ionizations in the medium. Gas phase studies thus appear as a very elegant solution, as they allow selecting the primary ionization event thanks to coincidence measurements $[12,13]$. However, it has been shown that the environment of the target molecule might have a strong influence on its fragmentation pattern [14].

$\mathrm{Ab}$ Initio Molecular Dynamics (MD) simulations may help interpreting how a specific primary physical event affects a biomolecule, such as a DNA or RNA building block, embedded in liquid water. Such methods have been applied to model the ultrafast fragmentation induced by a core vacancy, before Auger decay [15-17]. The method allows to target different atomic sites in the biomolecule (direct effect) or the atoms of neighboring water molecules (indirect effect). In parallel, tools were developed in order to model the fragmentation of doubly ionized molecules $[14,18,19]$. Note that this method enables removal of the two electrons from any outer shell molecular orbital (MO) of the sample. In the present paper, we will show how these two different methods may be combined to help the interpretation of synchrotron irradiation experiments. We will focus on a deoxyribose (DR) molecule embedded in liquid water. The sugar is in its furanose conformation, which is the form it adopts in DNA.

\section{Results}

\subsection{Ultrafast Dissociation of Core Ionized Deoxyribose}

In a previous paper [17], we have modeled the dynamics induced by the removal of oxygen K-shell electrons from a deoxyribose molecule embedded in liquid water (direct effect). The only investigated initial configuration (atomic positions and velocities) is shown in Figure 1. The C-O* bonds length increased by $0.1-0.2 \AA$ during the 9.7 fs dynamics (the asterisk will always indicate the core-ionized atom). The hydroxyl groups, however, displayed very different bond elongations, from $0.05 \AA$ for $\mathrm{O}^{*}-\mathrm{H} 3$ to $0.78 \AA$ for $5^{*}$-H5. To study indirect effects, two additional MD were performed, in which the core hole was localized on a water molecule donating an hydrogen bond (HB) either to $\mathrm{O} 1$ or $\mathrm{O} 4$. In both cases, one of the $\mathrm{O}^{*}-\mathrm{H}$ bonds broke during the $9.7 \mathrm{fs}$ dynamics, and the proton was transferred either to another water molecule or to $\mathrm{O} 4$, respectively.

In the present paper, we have completed this study by investigating five additional initial configurations, thus allowing a statistical analysis of the results. Core holes were localized on the different carbon and oxygen atoms of the sugar (direct effect). The results will be compared to simulations of the isolated molecule [20] to infer the role of the environment on the dissociation patterns. Core holes were also localized on the water molecules forming an HB with the sugar (indirect effect). 


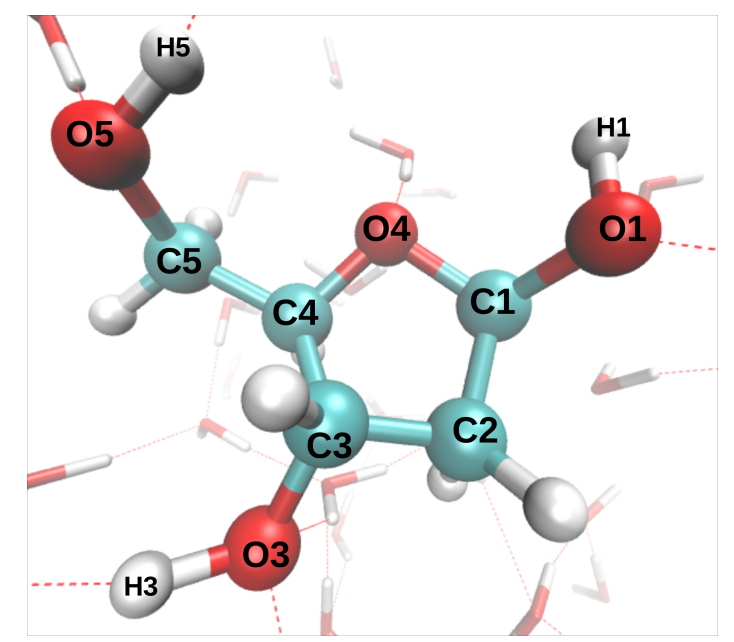

Figure 1. The initial configuration for the furanose conformation of deoxyribose previously investigated [17] and atom labeling.

\subsubsection{Hydration of the Sugar}

We present first the DR hydration during the 1.2 ps dynamics of the neutral system, along which the six initial configurations were selected. Such simulation time is short for a full analysis of the hydration but our purpose here is to describe the starting point for the ensuing nonequilibrium dynamics. The radial distribution functions (RDF) between the different DR oxygen atoms and the water hydrogen atoms exhibited a first minimum around $2.4 \AA$, as did the RDF between the different hydrogen atoms belonging to the DR hydroxyl groups and the water oxygen atoms (see Supplementary Materials, Figure S1). The number of water molecules in the first coordination sphere of the different DR atoms are shown in Table 1.

Table 1. First hydration layer of the DR ring oxygen and hydroxyl groups. Statistics was performed along a 1.2 ps MD of the neutral system.

\begin{tabular}{|c|c|c|}
\hline DR Group & $\begin{array}{c}\text { Number of Water Hydrogen Within } \\
2.4 \AA \text { of the DR Oxygen }\end{array}$ & $\begin{array}{c}\text { Number of Water Oxygen Within } \\
2.4 \AA \text { of the DR Hydrogen }\end{array}$ \\
\hline Ring oxygen (O4) & 0.93 & - \\
\hline $\mathrm{O} 1 \mathrm{H} 1$ & 1.74 & 1.0 \\
\hline $\mathrm{O} 3 \mathrm{H} 3$ & 1.95 & 1.0 \\
\hline O5H5 & 2.0 & 1.0 \\
\hline
\end{tabular}

\subsubsection{Direct Effect}

We have studied the consequence of carbon or oxygen K-shell ionizations in a deoxyribose molecule embedded in liquid water. Carbon K-shell vacancies did not induce any significant bond elongation during the $9.7 \mathrm{fs} \mathrm{MD}$. On the contrary, when the core hole is localized on the oxygen atoms, the length of the $\mathrm{CO}^{*}$ and $\mathrm{O}^{*} \mathrm{H}$ bonds systematically increases, as shown in Table 2 . The elongation of the $\mathrm{CO}^{*}$ bonds was always below $0.34 \AA$ at the end of all the $9.7 \mathrm{fs}$ core hole MD. These results are similar to those obtained in the gas phase [20]. Thus, the $\mathrm{CO}^{*}$ bonds elongation does not seem to be influenced much by the DR environment. In particular, the largest average bond elongation is induced by core vacancies on $\mathrm{O} 1$ in both phases.

On the contrary, although $\mathrm{O}^{*} \mathrm{H}$ bonds are not much affected by the presence of the K-shell vacancy on $\mathrm{O}^{*}$ in the gas phase [20], these bonds may undergo very large elongations in liquid water, as shown in Table 2. In fact, the elongation of the $\mathrm{O}^{*} \mathrm{H}$ bonds could reach $0.93 \AA$ at the end of the $9.7 \mathrm{fs}$ core hole dynamics. Considering $\mathrm{OH}$ bonds to be dissociated when the $\mathrm{OH}$ distance is larger than $1.5 \AA$, we find that the $\mathrm{O} 3-\mathrm{H} 3$ bond breaks in two configurations out of six, and the $\mathrm{O} 1-\mathrm{H} 1$ and $\mathrm{O} 5-\mathrm{H} 5$ bonds 
in four configurations out of six. The released proton is always transferred to a neighboring water molecule to form an hydronium ion $\left(\mathrm{H}_{3} \mathrm{O}^{+}\right)$.

Table 2. Average bond elongation due to the presence of a K-shell vacancy during $9.7 \mathrm{fs}$ on the oxygen atom $\mathrm{O}^{*}$ of a DR molecule embedded in water. Statistics performed on 6 different initial configurations.

\begin{tabular}{ccccc}
\hline O$^{*}$ & Bond & Elongation $(\AA)$ & Bond & Elongation $(\AA)$ \\
\hline $\mathrm{O} 1$ & $\mathrm{C} 1-\mathrm{O} 1$ & $0.22 \pm 0.10 \AA$ & $\mathrm{O} 1-\mathrm{H} 1$ & $0.57 \pm 0.29 \AA$ \\
$\mathrm{O} 3$ & $\mathrm{C} 3-\mathrm{O} 3$ & $0.17 \pm 0.05 \AA$ & $\mathrm{O} 3-\mathrm{H} 3$ & $0.34 \pm 0.29 \AA$ \\
$\mathrm{O} 4$ & $\mathrm{C} 1-\mathrm{O} 4$ & $0.17 \pm 0.02 \AA$ & $\mathrm{C} 4-\mathrm{O} 4$ & $0.13 \pm 0.03 \AA$ \\
$\mathrm{O} 5$ & $\mathrm{C} 5-\mathrm{O} 5$ & $0.15 \pm 0.03 \AA$ & $\mathrm{O} 5-\mathrm{H} 5$ & $0.53 \pm 0.34 \AA$ \\
\hline
\end{tabular}

The dissociation of $\mathrm{O}^{*} \mathrm{H}$ bonds appears to depend strongly on the local environment of the hydroxyl groups, and, more specifically, on the presence of a water molecule (labeled $\mathrm{H}_{2} \mathrm{O}_{w}$ ) accepting an hydrogen bond from the sugar $\left(\mathrm{O}^{*} \mathrm{H} \ldots \mathrm{O}_{w}\right)$. When the initial distance between the DR hydrogen atom and $\mathrm{O}_{w}$ is less than $\sim 1.8 \AA$, respectively, greater than $\sim 1.9 \AA$, the DR hydroxyl group $\left(\mathrm{O}^{*} \mathrm{H}\right)$ always, respectively, never, dissociates to form $\mathrm{H}_{3} \mathrm{O}_{w}^{+}$. A similar influence of hydration on $\mathrm{NH}$ bond dissociation was found in a uracil molecule embedded in water, when the core hole was localized on the nitrogen atoms [16].

\subsubsection{Indirect Effect}

We have investigated the ultrafast dissociation of the water molecules which belong to the deoxyribose primary hydration shell, after a core ionization was placed on the oxygen atom $\left(\mathrm{O}^{*}\right)$, but before Auger decay. One of the $\mathrm{O}^{*} \mathrm{H}$ bonds always exhibits a longer elongation than the other. It reaches on average $1.66 \pm 0.23 \AA$ at $\mathrm{t}=9.7 \mathrm{fs}$, compared to $1.12 \pm 0.19 \AA$ for the second bond. These values do not seem to depend on whether the water molecule accepts or donates an HB to the sugar. The species formed at the end of the $9.7 \mathrm{fs}$ dynamics are listed in Table 3.

Table 3. Species formed after a core ionization was placed during $9.7 \mathrm{fs}$ on a water molecule hydrogen bonded to a DR molecule embedded in water. Statistics performed on 6 different initial configurations.

\begin{tabular}{|c|c|c|c|c|}
\hline $\begin{array}{l}\text { The Core-Ionized } \\
\text { Water Molecule }\end{array}$ & $\begin{array}{l}\text { Number } \\
\text { of MD }\end{array}$ & $\begin{array}{c}\text { A Proton is } \\
\text { Emitted Towards }\end{array}$ & Species Formed & Occurrence \\
\hline \multirow[b]{2}{*}{$\begin{array}{l}\text { donates an HB to the } \\
\text { DR ring oxygen }\end{array}$} & \multirow[b]{2}{*}{6} & DR & $\mathrm{DR}-\mathrm{H}^{+}+\mathrm{O}^{*} \mathrm{H}$ & 2 \\
\hline & & $\mathrm{H}_{2} \mathrm{O}$ & $\begin{array}{c}\mathrm{H}_{3} \mathrm{O}^{+}+\mathrm{O}^{*} \mathrm{H} \\
\left(\mathrm{H}_{2} \mathrm{O}-\mathrm{H}-\mathrm{O}^{*} \mathrm{H}\right)^{+}\end{array}$ & $\begin{array}{l}2 \\
1\end{array}$ \\
\hline \multirow{3}{*}{$\begin{array}{l}\text { donates an HB to the } \\
\text { DR hydroxyl groups }\end{array}$} & \multirow{3}{*}{31} & DR & $\begin{array}{l}\mathrm{DR}-\mathrm{H}^{+}+\mathrm{O}^{*} \mathrm{H} \\
\left(\mathrm{DR}-\mathrm{H}-\mathrm{O}^{*} \mathrm{H}\right)^{+}\end{array}$ & $\begin{array}{l}5 \\
1\end{array}$ \\
\hline & & $\mathrm{H}_{2} \mathrm{O}$ & $\begin{array}{c}\mathrm{H}_{3} \mathrm{O}^{+}+\mathrm{O}^{*} \mathrm{H} \\
\left(\mathrm{H}_{2} \mathrm{O}-\mathrm{H}-\mathrm{O}^{*} \mathrm{H}\right)^{+}\end{array}$ & $\begin{array}{c}15 \\
2\end{array}$ \\
\hline & & $\mathrm{DR}, \mathrm{H}_{2} \mathrm{O}$ & $\begin{array}{c}\mathrm{DR}-\mathrm{H}^{+}+\mathrm{O}^{*}-\mathrm{H}-\mathrm{OH}_{2} \\
\mathrm{DR}-\mathrm{H}-\mathrm{O}^{*}+\mathrm{H}_{3} \mathrm{O}^{+} \\
\left(\mathrm{DR}-\mathrm{H}-\mathrm{O}^{*}-\mathrm{H}-\mathrm{OH}_{2}\right)^{+}\end{array}$ & $\begin{array}{l}2 \\
4 \\
1\end{array}$ \\
\hline \multirow[b]{2}{*}{$\begin{array}{l}\text { accepts an HB from the } \\
\text { DR hydroxyl groups }\end{array}$} & \multirow[b]{2}{*}{18} & $\mathrm{H}_{2} \mathrm{O}$ & $\begin{array}{c}\mathrm{H}_{3} \mathrm{O}^{+}+\mathrm{O}^{*} \mathrm{H} \\
\left(\mathrm{H}_{2} \mathrm{O}-\mathrm{H}-\mathrm{O}^{*} \mathrm{H}\right)^{+}\end{array}$ & $\begin{array}{l}8 \\
3\end{array}$ \\
\hline & & $\mathrm{H}_{2} \mathrm{O}, \mathrm{H}_{2} \mathrm{O}$ & $\begin{array}{c}2 \mathrm{H}_{3} \mathrm{O}^{+}+\mathrm{O}^{*-} \\
\mathrm{H}_{3} \mathrm{O}^{+}+\mathrm{O}^{*}-\mathrm{H}-\mathrm{OH}_{2} \\
\left(\mathrm{H}_{2} \mathrm{O}-\mathrm{H}-\mathrm{O}^{*}-\mathrm{H}-\mathrm{OH}_{2}\right)^{+}\end{array}$ & $\begin{array}{l}1 \\
3 \\
1\end{array}$ \\
\hline
\end{tabular}

Let us consider the water molecules which donate an HB to the sugar. In most cases (24/37), the core-ionized water molecule emits only one proton, either towards the sugar $\left(\mathrm{DR}-\mathrm{H}^{+}+\mathrm{O}^{*} \mathrm{H}\right)$ or towards another water molecule $\left(\mathrm{H}_{3} \mathrm{O}^{+}+\mathrm{O}^{*} \mathrm{H}\right)$. In a few additional cases $(4 / 37)$, the emitted hydrogen is less than $1.5 \AA$ away from both the core-ionized and $\mathrm{HB}$ acceptor molecules $\left(\left(\mathrm{DR}-\mathrm{H}-\mathrm{O}^{*} \mathrm{H}\right)^{+}\right.$ 
or $\left.\left(\mathrm{H}_{2} \mathrm{O}-\mathrm{H}-\mathrm{O}^{*} \mathrm{H}\right)^{+}\right)$. More rarely, both $\mathrm{O}^{*} \mathrm{H}$ bonds undergo significant elongation (in seven cases out of 37).

Let us now consider the water molecules which accept an HB from the sugar hydroxyl groups. In 11 cases, the water molecule has one broken bond leading to the formation of an $\mathrm{H}_{3} \mathrm{O}^{+}$, the second $\mathrm{O}^{*} \mathrm{H}$ bond is significantly elongated in 3 out of these $11 \mathrm{MD}$. One dynamics results in the complete fragmentation of the core-ionized molecule.

As a conclusion, two species are formed $\left(\mathrm{O}^{*} \mathrm{H}\right.$ and $\left.\mathrm{H}_{3} \mathrm{O}^{+}\right)$in the vicinity of the sugar, and/or protons may be transferred towards the sugar during the lifetime of the core vacancy. The species thus formed could in turn damage the sugar by an indirect effect. It should however be mentioned that, in most cases, Auger decay will take place well before the molecules dissociation since the lifetime of a K-shell vacancy is $\simeq 4.1 \mathrm{fs}$ in water [21]. We have in fact estimated that, in liquid water, only $\sim 16 \%$ of the core-ionized water molecules will have one or both $\mathrm{O}_{w}^{*} \mathrm{H}$ bonds broken before Auger decay [16].

\subsection{Dissociation of Doubly Ionized DR after Auger Effect}

How to localize the double hole after Auger effect? In Born Oppenheimer MD (BOMD), one cannot localize the initial charges on a single molecule in the condensed phase. The Ehrenfest time-dependent density functional theory (TDDFT) method must thus be applied to propagate a dicationic electronic state prepared by emptying one of the localized valence molecular orbitals of the sample [18]. It has to be noticed that Auger effect can lead to many different channels since the Auger electron can be ejected from different orbitals. The calculation of the branching ratios of the Auger deexcitation channels would be prohibitive in view of the number of MO of the system. Here, we chose to remove the two electrons from the deepest valence MO localized on the oxygen atom which had the K-shell vacancy before Auger decay $\left(\mathrm{O}^{*}\right)$. Although the selected deexcitation process might not be the most probable, it is the most energetic leading to the fastest fragmentation process, and it may thus be modeled in a reasonable computational time.

As this method is very computationally consuming, we restrict our study to a single initial configuration, and to the dissociation induced by the removal of a K-shell electron from the DR oxygen atoms (direct effects). The initial configuration $(t=0)$ is the one shown in Figure 1 , and the four core-hole dynamics, one for each oxygen atom, are those described in details in [17]. The geometry of the sugar evolves while the oxygen atom has a K-shell vacancy. In fact, the $\mathrm{O}^{*} \mathrm{H}$ bond is broken at the end of two out of the four core-hole dynamics. It should however be stressed that the lifetime of the oxygen $\mathrm{K}$ vacancy is only $4.7 \mathrm{fs}$ [22]. As a consequence, approximately $87 \%$ of the core-ionized molecules undergo Auger decay before 9.7 fs. Furthermore, Auger decay will most probably happen almost immediately after core ionization, so that the $\mathrm{DR}^{2+}$ geometry will be very similar to that of the initial configuration (shown in Figure 1). We have therefore modeled two extreme scenarios. In the first scenario, the DR undergoes Auger decay at $t=0$, when no structural change has been induced by the K-shell vacancy. We have thus performed four $\mathrm{DR}^{2+}$ Ehrenfest TDDFT MD, all starting with the same geometry, that is the initial configuration shown in Figure 1, but removing the two electrons from each of the four deepest valence MO localized on the DR oxygen atoms. In the second scenario, the DR undergoes Auger decay at the end of the $9.7 \mathrm{fs}$ core hole dynamics, when the structural change induced by the $\mathrm{K}$ vacancy is maximal. We have thus performed four $\mathrm{DR}^{2+}$ Ehrenfest TDDFT MD, starting from four different geometries, those generated at the end of the four core hole dynamics, and removing the two electrons from the deepest valence $\mathrm{MO}$ localized on the core-ionized atom $\left(\mathrm{O}^{*}\right)$.

Figure 2 shows the dissociation dynamics induced by a double hole localized on the DR ring oxygen $(\mathrm{O} 4)$ after Auger decay. In the first scenario (Figure 2, top), the O4 core hole decays at $\mathrm{t}=0$. The C1-O4 and C4-O4 bonds then break very rapidly, at 8.7 and $9.0 \mathrm{fs}$, respectively. It should be noted that these bonds only elongated by 0.14 and $0.18 \AA$, respectively, when a core hole was localized on $\mathrm{O} 4$ during $9.7 \mathrm{fs}$. In the second scenario (Figure 2, bottom), the O4 core hole decays at $9.7 \mathrm{fs}$. The C1-O4 and $\mathrm{C} 4-\mathrm{O} 4$ bonds then break at 15.4 and $18.9 \mathrm{fs}$, respectively. The presence of a core vacancy on $\mathrm{O} 4$ 
thus seems only to delay the dissociation of the C-O4 bonds. In both scenarios, the O5-H5 bond length increases slightly during the $9.6 \mathrm{fs} \mathrm{DR}^{2+}$ dynamics, whereas the O1-H1 elongates more in the first scenario than in the second.

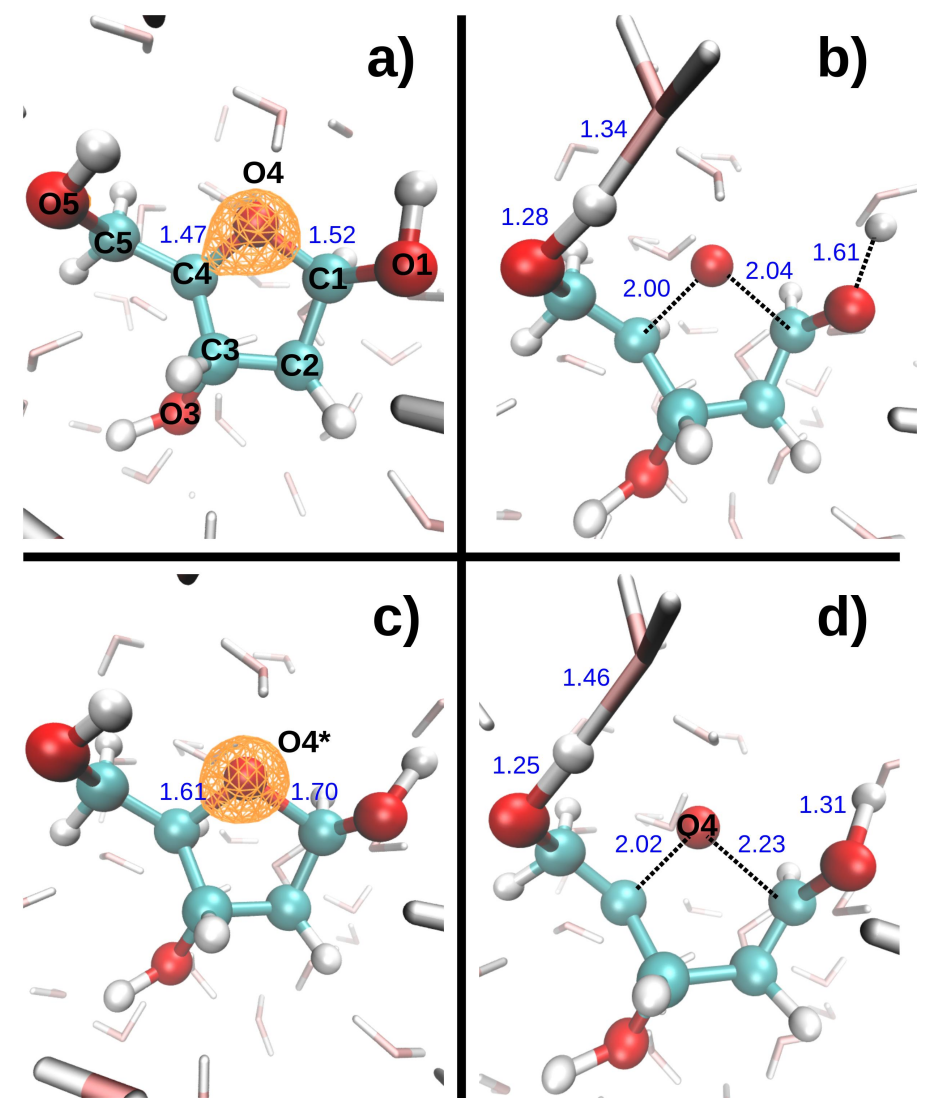

Figure 2. Top: $\mathrm{DR}^{2+}$ dynamics initiated from the initial configuration. (a) Initial configuration [17] and MO from which the electrons are removed (orange contour). (b) Configuration at the end of the $\mathrm{DR}^{2+}$ TDDFT dynamics $(t=9.6 \mathrm{fs})$. Bottom: $\mathrm{DR}^{2+}$ dynamics after a core hole was localized on $\mathrm{O} 4 \mathrm{for} 9.7 \mathrm{fs}$. (c) Configuration at the end of the core hole dynamics ( $t=9.7 \mathrm{fs}$, [17]) and MO from which the electrons are removed (orange contour). (d) Configuration at the end of the $\mathrm{DR}^{2+}$ TDDFT dynamics ( $t=19.3 \mathrm{fs}$ ). Distances in Angström are displayed in blue font.

Figure 3 shows the dissociation dynamics induced by a double hole localized on O1 after Auger decay. In the first scenario (Figure 3, top), the O1 core hole decays at $\mathrm{t}=0$. The O1-H1 and C1-O1 bonds then break within a few femtoseconds (see Table 4). H1 first collides on a neighboring water oxygen $\left(\mathrm{O}_{w 1}\right)$ at $\sim 5 \mathrm{fs}$, after which it moves further away from $\mathrm{O} 1$. The kinetic energy of $\mathrm{H} 1$ exhibits large variations. It first increases up to a maximum value of $5.3 \mathrm{eV}$ as $\mathrm{H} 1$ departs from the DR. It then decreases to a minimum value of $2.6 \mathrm{eV}$ when $\mathrm{H} 1$ is closest to the water molecule. After the collision, it reaches a second maximum of $4.3 \mathrm{eV}$, and then gradually decreases again. Meanwhile, the kinetic energy of $\mathrm{O} 1$ increases up to $0.1 \mathrm{eV}$ during about $5 \mathrm{fs}$, and then remains fairly constant. In the second scenario (Figure 3, bottom), the $\mathrm{O} 1$ core hole decays at $9.7 \mathrm{fs}$. It should be noted that the O1-H1 bond breaks during the O1 core-hole dynamics, at $\mathrm{t}=8.7 \mathrm{fs}$ (see Table 4). During the subsequent $\mathrm{DR}^{2+}$ dynamics, $\mathrm{H} 1$ also collides with $\mathrm{O}_{w 1}$, but it is retrodiffused back towards $\mathrm{O} 1$ so that the $\mathrm{O} 1-\mathrm{H} 1$ bond forms again at $\mathrm{t}=15.0 \mathrm{fs}$. In the meantime, the $\mathrm{C} 1-\mathrm{O} 1$ bond elongates up to $1.86 \AA$ at $\mathrm{t}$ $=19.3 \mathrm{fs}$. The maximum kinetic energy reached by both $\mathrm{H} 1$ and $\mathrm{O} 1$ is lower in the second than in the first scenario (see Table 4). 


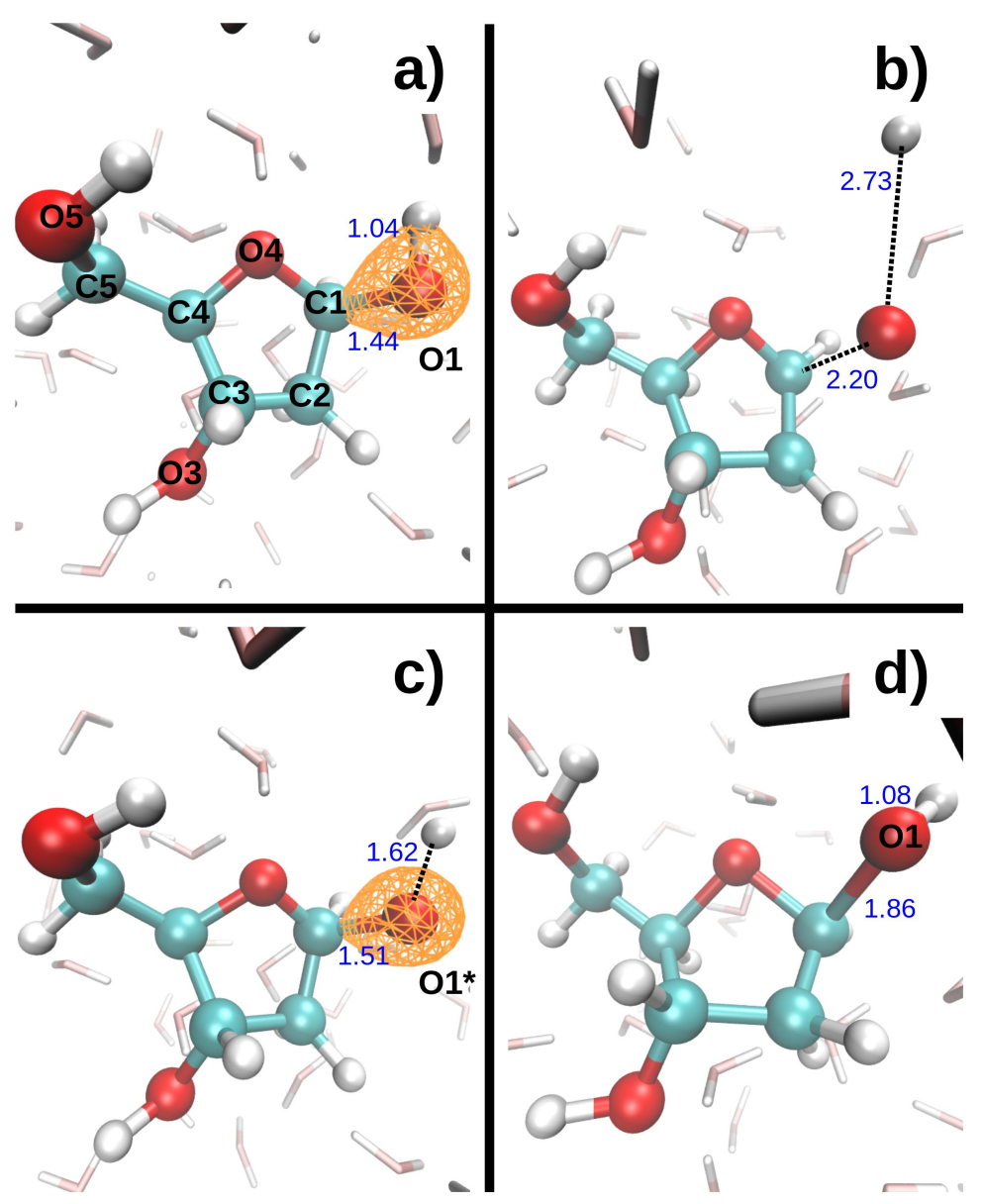

Figure 3. Top: $\mathrm{DR}^{2+}$ dynamics initiated from the initial configuration. (a) Initial configuration [17] and MO from which the electrons are removed (orange contour). (b) Configuration at the end of the $\mathrm{DR}^{2+}$ TDDFT dynamics $(t=9.6 \mathrm{fs})$. Bottom: $\mathrm{DR}^{2+}$ dynamics after a core hole was localized on $\mathrm{O} 1 \mathrm{for} 9.7 \mathrm{fs}$. (c) Configuration at the end of the core hole dynamics ( $t=9.7 \mathrm{fs},[17])$ and $\mathrm{MO}$ from which the electrons are removed (orange contour). (d) Configuration at the end of the $\mathrm{DR}^{2+}$ TDDFT dynamics ( $t=19.3 \mathrm{fs}$ ). Distances in Angström are displayed in blue font.

Table 4. Dissociation dynamics after a core hole was placed on $\mathrm{O} 1$ at $\mathrm{t}=0$.

\begin{tabular}{ccccc}
\hline $\begin{array}{c}\text { Auger Decay } \\
\text { Time (fs) }\end{array}$ & \multicolumn{2}{c}{ Dissociation Time (fs) } & \multicolumn{2}{c}{ Maximum Kinetic Energy (eV) } \\
O1-H1 & C1-O1 & H1 & O1 \\
\hline 0 & 2.7 & 7.5 & 5.3 & 0.10 \\
9.7 & 8.7 & - & 0.98 & 0.05 \\
\hline
\end{tabular}

Figure 4 shows the dissociation dynamics induced by a double hole localized on $\mathrm{O} 3$ after Auger decay. In the first scenario (Figure 4, top), the O3 core hole decays at $\mathrm{t}=0$. The O3-H3 and C3-O3 bonds then break within a few femtoseconds (see Table 5). H3 first collides with a neighboring water oxygen $\left(\mathrm{O}_{w 3}\right)$ at $\sim 6.3 \mathrm{fs}$, but the deviation angle is small and it moves further away from O3. In the second scenario (Figure 4, bottom), the $\mathrm{O} 3$ core hole decays at $9.7 \mathrm{fs}$. The O3-H3 and C3-O3 bonds only elongate slightly during the $\mathrm{O} 3$ core hole dynamics, but then break very rapidly during the subsequent $\mathrm{DR}^{2+}$ dynamics (see Table 5). $\mathrm{H} 3$ collides with $\mathrm{O}_{w 3}$ at $\sim 14.8 \mathrm{fs}$. The deviation angle is larger than in the first scenario, but $\mathrm{H} 3$ also moves away from $\mathrm{O} 3$ after the collision. The maximum kinetic energy reached by both $\mathrm{H} 3$ and $\mathrm{O} 3$ is lower in the second than in the first scenario (see Table 5). Interestingly, a bond forms between $\mathrm{C} 3$ and $\mathrm{O} 4$ in both scenarios. 


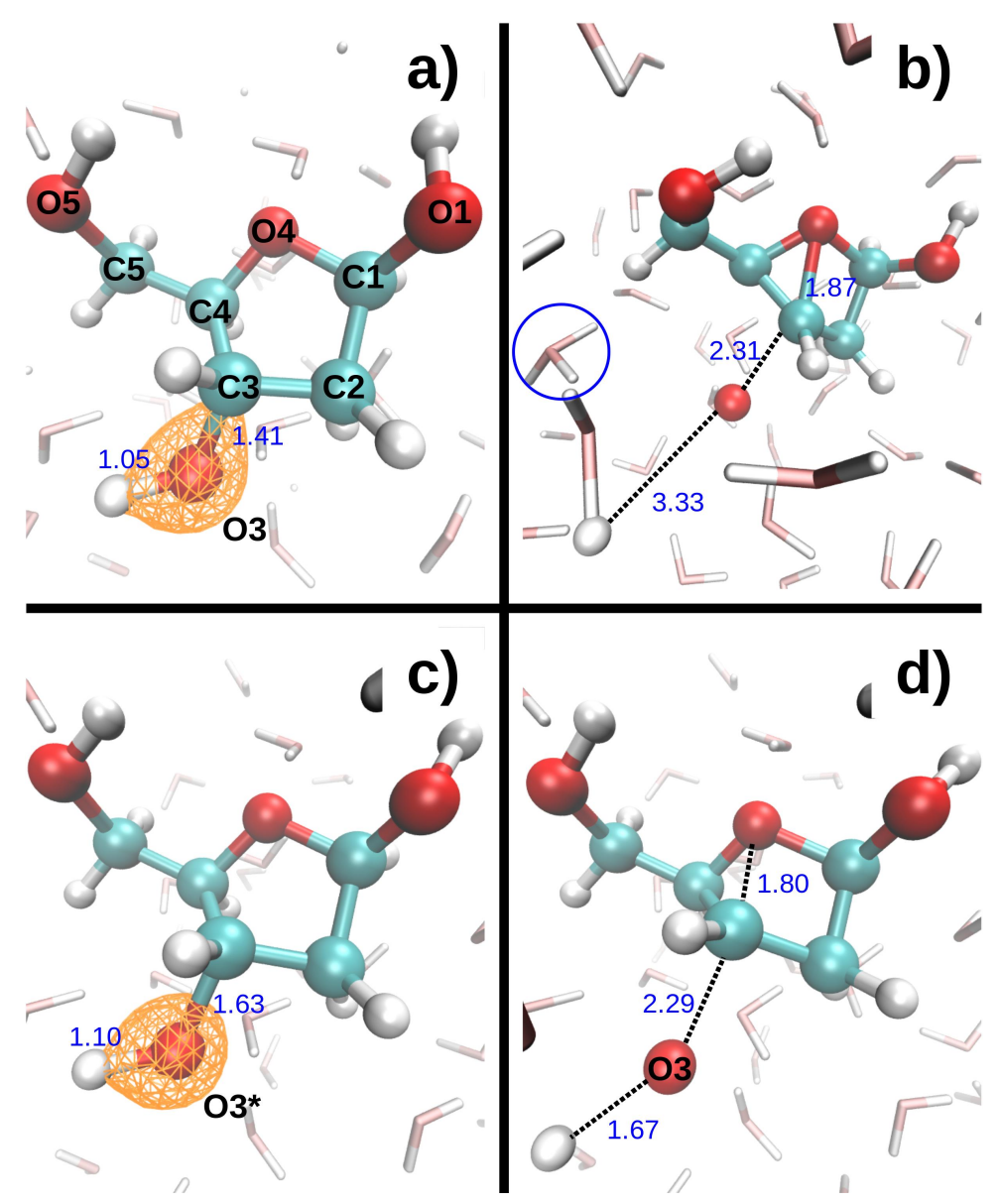

Figure 4. Top: $\mathrm{DR}^{2+}$ dynamics initiated from the initial configuration. (a) Initial configuration [17] and MO from which the electrons are removed (orange contour). (b) Configuration at the end of the $\mathrm{DR}^{2+}$ TDDFT dynamics $(t=9.7 \mathrm{fs})$. Bottom: $\mathrm{DR}^{2+}$ dynamics after a core hole was localized on $\mathrm{O} 3$ for $9.7 \mathrm{fs}$. (c) Configuration at the end of the core hole dynamics ( $\mathrm{t}=9.7 \mathrm{fs},[17])$ and $\mathrm{MO}$ from which the electrons are removed (orange contour). (d) Configuration at the end of the $\mathrm{DR}^{2+}$ TDDFT dynamics ( $t=19.3 \mathrm{fs}$ ). Distances in Angström are displayed in blue font.

Table 5. Dissociation dynamics after a core hole was placed on $\mathrm{O} 3$ at $\mathrm{t}=0$.

\begin{tabular}{ccclc}
\hline $\begin{array}{c}\text { Auger Decay } \\
\text { Time (fs) }\end{array}$ & \multicolumn{2}{c}{ Dissociation Time (fs) } & \multicolumn{2}{c}{ Maximum Kinetic Energy (eV) } \\
O3-H3 & C3-O3 & H3 & O3 \\
\hline 0 & 3.0 & 7.0 & 5.7 & 0.15 \\
9.7 & 12.3 & 15.6 & 4.9 & 0.08 \\
\hline
\end{tabular}

Figure 5 shows the dissociation dynamics induced by a double hole localized on O5 after Auger decay. In the first scenario (Figure 5, top), the O5 core hole decays at $\mathrm{t}=0$. The O5-H5 and C5-O5 bonds then break within a few femtoseconds (see Table 6). H5 first collides on a neighboring water oxygen $\left(\mathrm{O}_{w 5}\right)$. It is then scattered back towards $\mathrm{O} 5$ so that the $\mathrm{O} 5-\mathrm{H} 5$ distance diminishes towards the end of the dynamics. In the second scenario (Figure 5, bottom), the O5 core hole decays at $9.7 \mathrm{fs}$. It should be noted that the O5-H5 bond breaks during the $\mathrm{O} 5$ core-hole dynamics, at $\mathrm{t}=6.1 \mathrm{fs}$. $\mathrm{H} 5$ then binds to $\mathrm{O}_{w 5}$. This bond undergoes large vibrations, between 0.81 and $1.26 \AA$, but $\mathrm{H} 5$ remains bound to $\mathrm{O}_{w 5}$ during the subsequent $\mathrm{DR}^{2+}$. The C5-O5 bond breaks at $16.6 \mathrm{fs}$. The maximum kinetic energy reached by both $\mathrm{H} 5$ and $\mathrm{O} 5$ is lower in the second than in the first scenario (see Table 5). 


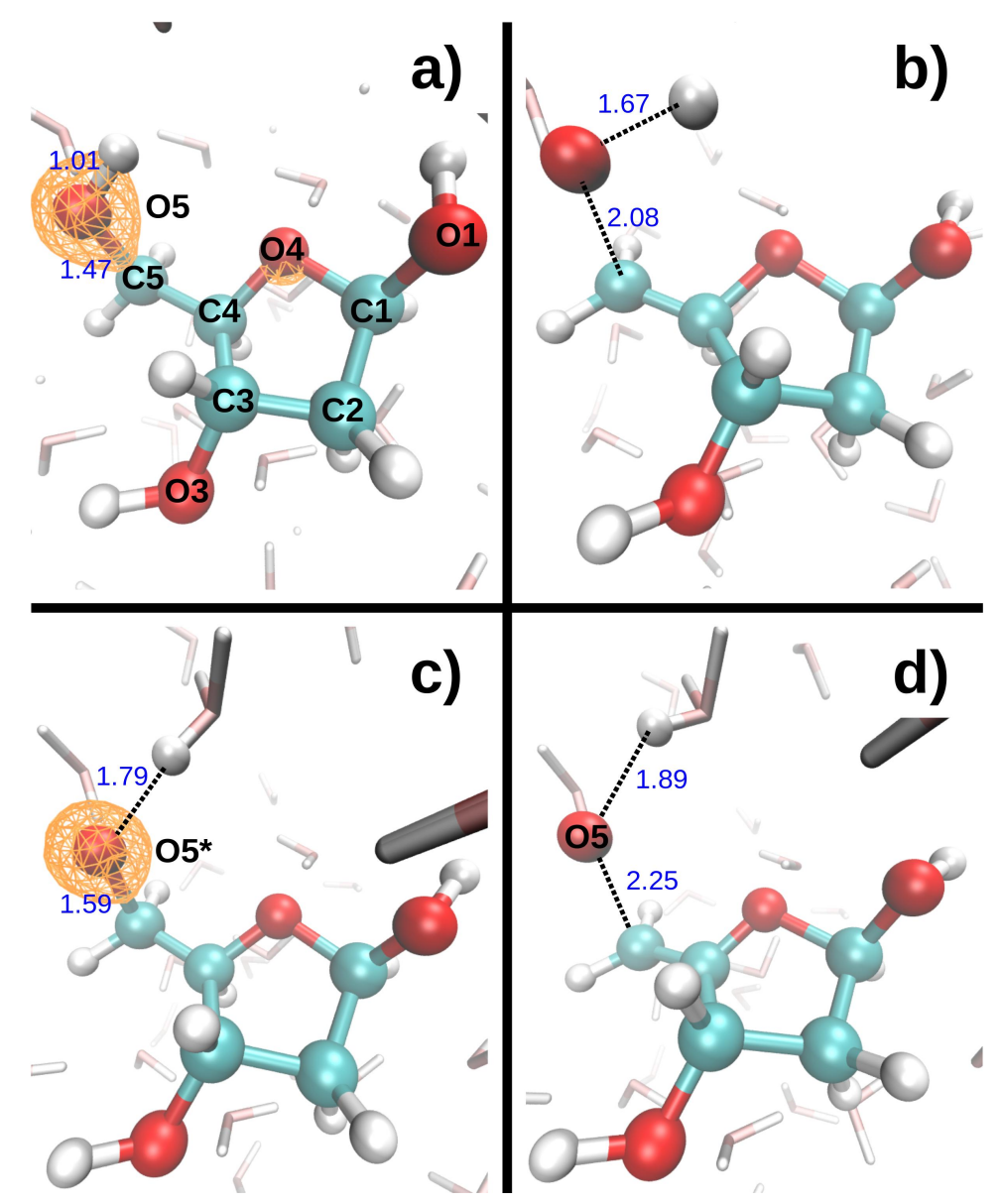

Figure 5. Top: $\mathrm{DR}^{2+}$ dynamics initiated from the initial configuration. (a) Initial configuration [17] and MO from which the electrons are removed (orange contour). (b) Configuration at the end of the $\mathrm{DR}^{2+}$ TDDFT dynamics $(t=9.7 \mathrm{fs})$. Bottom: $\mathrm{DR}^{2+}$ dynamics after a core hole was localized on $\mathrm{O} 5$ for $9.7 \mathrm{fs}$. (c) Configuration at the end of the core hole dynamics ( $t=9.7 \mathrm{fs},[17])$ and $\mathrm{MO}$ from which the electrons are removed (orange contour). (d) Configuration at the end of the $\mathrm{DR}^{2+}$ TDDFT dynamics ( $t=19.3 \mathrm{fs}$ ). Distances in Angström are displayed in blue font.

Table 6. Dissociation dynamics after a core hole was placed on $\mathrm{O} 5$ at $\mathrm{t}=0$.

\begin{tabular}{ccclc}
\hline $\begin{array}{c}\text { Auger Decay } \\
\text { Time (fs) }\end{array}$ & \multicolumn{2}{c}{ Dissociation Time (fs) } & \multicolumn{2}{c}{ Maximum Kinetic Energy (eV) } \\
O5-H5 & C5-O5 & H5 & O5 \\
\hline 0 & 2.8 & 8.6 & 4.6 & 0.06 \\
9.7 & 6.1 & 16.6 & 1.3 & 0.08 \\
\hline
\end{tabular}

To summarize, when a double hole is localized on the DR oxygen atoms, the bonds involving this oxygen atom are very rapidly broken, typically after $3 \mathrm{fs}$ for the $\mathrm{OH}$ bonds, and 7 to $9 \mathrm{fs}$ for the $\mathrm{CO}$ bonds. The elongation of these bonds is much faster than that induced by a core vacancy on the same oxygen atom. Moreover, in most cases, the $\mathrm{CO}$ bond breakage during the $\mathrm{DR}^{2+}$ dynamics does not seem to depend much on the time at which Auger decay occurs. This is not the case for the protons dynamics. For one part, their kinetic energy is lower when the $\mathrm{OH}$ bond breaks during the core hole dynamics, than when it breaks during the $\mathrm{DR}^{2+}$ dynamics. However, the protons trajectories also differ when the $\mathrm{OH}$ bond breaks after Auger decay in the two scenarios. In fact, we have recently shown that the trajectories of the protons ejected from an $\mathrm{H}_{2} \mathrm{O}^{2+}$ molecule are very sensitive to slight perturbations of the system [19]. 


\section{Discussion}

Different theoretical methods have been used to understand the fragmentation of molecules after $\mathrm{K}$-shell ionization and Auger effect. In many cases, the fragmentation of molecules upon inner-shell ionization is not specific with respect to the initially localized ionization site, in contrast with the case of $\mathrm{ClCH}_{2} \mathrm{Br}$ where a strong site-specific fragmentation was observed [23]. In a recent publication [24], the lack of site specificity was attributed to the character of the dicationic electronic states after Auger decay in the case of ethyl trifluoroacetate molecule. This could be proved by a calculation of the Auger rates for the many involved final dicationic electronic states after Auger effect. In the gas phase and for small molecules, this kind of calculations is feasible. In many cases, statistical methods are used [25], where fast conversion processes quickly transfer electronic excitation energy of the dication into vibrational degrees of freedom. In these models, the identities of the electronic states populated via Auger decay are not taken into account, and the only important parameter determining the fragmentation remains the internal energy.

All these modeling methods are used for $\mathrm{K}$ holes induced in gas phase molecules. When a molecule is embedded in water, calculating Auger rates seems hardly computationally practicable in view of the number of atoms. The effect of the solvent has to be taken into account since even transfer of charges can take place during the $\mathrm{K}$ hole dynamics (10 fs), so we performed core hole molecular dynamics with $\mathrm{K}$ holes on the different atoms of the DR and on different configurations of the DR embedded in water and on different water molecules of the solvent. This allowed us to exhibit cases where transfer of charge from the molecule to the solvent is produced before Auger effect. As the localization of the charge after Auger decay may have a key role in the fragmentation of the dication we prolongated the K hole dynamics by a TDDFT Ehrenfest MD where the initial state is dicationic by emptying the most energetic valence orbital. TDDFT Ehrenfest MD propagate the wavefunction calculating the mean forces at each step, ensuring the propagation of distribution of charges. As a first trial we only emptied the most energetic valence orbital around the oxygen atoms where the $\mathrm{K}$ hole was located at the end of the K hole dynamics. In the major part of our simulation we noticed no specificity of the localization of the K hole. However, a study of less energetic emptied orbital has to be achieved in a forthcoming publication in comparison with initial configuration without a $\mathrm{K}$ hole and the same emptied orbital.

Indeed this study is not exhaustive but it allowed to exhibit some particular trends on the effect of $\mathrm{K}$ hole versus Auger effect. We have studied the dynamics of a core-ionized deoxyribose molecule embedded in liquid water and as a first conclusion we can notice that carbon K-shell vacancies did not induce any systematic change in the molecules geometry during the $10 \mathrm{fs} \mathrm{MD}$. On the contrary, oxygen $\mathrm{K}$-holes always induced an elongation of the $\mathrm{CO}^{*}$ and $\mathrm{O}^{*} \mathrm{H}$ bonds. The $\mathrm{CO}^{*}$ bond length increased by $0.17 \pm 0.06$ on average during the $10 \mathrm{fs} \mathrm{MD}$, a behavior very similar to that of the isolated molecule [20]. $\mathrm{O}^{*} \mathrm{H}$ bond lengths exhibited much larger variations, increasing between 0.04 and $0.93 \AA$ during the $10 \mathrm{fs}$ MD. These variation may be related to the initial hydration state of the core-ionized hydroxyl groups. In fact, $\mathrm{O}^{*} \mathrm{H}$ bonds did not elongate in the isolated molecule [20]. In water molecules, the oxygen core vacancy often leads to the dissociation of at least one of the two $\mathrm{O}_{w}^{*} \mathrm{H}$ bonds during the lifetime of the core vacancy ( $\simeq 4.1 \mathrm{fs}$ in water [21]). In such cases, the proton is ejected either towards the sugar to form $\mathrm{DR}-\mathrm{H}^{+}$or towards another water molecule to form $\mathrm{H}_{3} \mathrm{O}^{+}$.

The removal of two electrons from the deepest valence orbital localized on the DR oxygen atoms leads to a very fast dissociation of the $\mathrm{CO}$ bonds involving the core-ionized atom. In most cases, this effect does not seem to depend on the time at which Auger decay occurs. Within $10 \mathrm{fs}$ after Auger decay, the sugar thus loses the ring oxygen when the double hole is localized on $\mathrm{O} 4$, and the hydroxyl groups when the double hole is localized on $\mathrm{O} 1, \mathrm{O} 3$ or $\mathrm{O} 5$.

\section{Materials and Methods}

All simulations were performed in the microcanonical ensemble with the plane-wave Kohn-Sham-based DFT Car-Parrinello molecular dynamics code CPMD [26]. Core electrons were 
replaced by pseudopotentials of the Trouiller-Martins form [27]. The Kleinman-Bylander integration scheme was used for all atom type. The exchange and correlation energy was calculated using the generalized gradient approximation (GGA) functional Becke-Lee-Yang-Parr (BLYP) [28,29]. The long-range electrostatic potential was computed using the standard Ewald summation scheme and a compensating background was thus used for the charged simulations.

The system consists of one deoxyribose molecule and 58 water molecules enclosed in a periodically repeated cubic box of size $12.43 \AA$. The initial configurations for the dynamics of the ionized system were extracted from a 1.2 ps Car-Parrinello MD of the neutral system [26] that followed a 5 ps long equilibration [17]. Both equilibration and initial CPMD dynamics were performed with $0.024 \mathrm{fs}$ timesteps and 100 au fictitious electronic mass. Except when otherwise stated, the plane-wave basis set was truncated at an energy cutoff of $70 \mathrm{Ry}\left(\mathrm{Ry}: 1 \mathrm{Ry}=2.17989 \times 10^{18} \mathrm{~J}\right)$. The average temperature of the systems was $324 \pm 13 \mathrm{~K}$. We have selected five different configurations (atomic positions and velocities) separated by $240 \mathrm{fs}$ time intervals, which were used as initial configurations for the core hole dynamics in order to take into account different degrees of hydration of the deoxyribose.

Briefly, the removal of K-shell electrons from the deoxyribose molecules was described by substituting the $1 \mathrm{~s}^{2}$ pseudopotential of one of the carbon or oxygen atoms of the molecule by a pseudopotential corresponding to a $1 \mathrm{~s}^{1}$ state at $t=0$. The atomic positions and velocities are assumed to be the same as those of the neutral molecule before ionization (vertical transition). The lifetime of a carbon K-shell vacancy is $8.24 \mathrm{fs}$, whereas that of oxygen is $4.71 \mathrm{fs}$ [22]. Born Oppenheimer MD were thus performed for $9.7 \mathrm{fs}$, with a $0.024 \mathrm{fs}$ timestep, and an energy cutoff of $110 \mathrm{Ry}$. For each initial configuration investigated, we have placed a core hole on each of the five carbon and four oxygen atoms of the sugar, and also on the oxygen atoms of the water molecules forming an hydrogen bond with the sugar. One-hundred-and-three BOMD were thus generated in addition to the six dynamics presented in paper [17].

We have studied the fragmentation induced not only by the presence of a core hole on the sugar oxygen atoms, but also by the double vacancy following Auger decay. To do so, the effective Wannier orbitals $[30,31]$ of all the molecules in the sample were determined for the configuration at the end of the core hole dynamics, that is at $\mathrm{t}=9.7 \mathrm{fs}$. After this, the pseudopotential corresponding to the $1 \mathrm{~s}^{1}$ state of the core-ionized atom was replaced by a $1 \mathrm{~s}^{2}$ pseudopotential. The initial nonstationary electronic state of the doubly charged sample is prepared by removing two electrons from the deepest valence MO localized on $\mathrm{O}^{*}$ [18]. We have selected that MO among all the possible channels of deexcitation because it is the most violent event and by consequence the quickest of all possible events. The deoxyribose molecule is doubly ionized, while all the other molecules of the sample remain strictly neutral. The electronic structure is then propagated for $9.6 \mathrm{fs}$ by Ehrenfest dynamics [32,33]. In our calculations, the numerical integration of the time-dependent Kohn-Sham equations was performed using an iterative Crank-Nicholson algorithm with a time step of $\Delta \mathrm{t} \leq 0.00024 \mathrm{fs}$ combined with a two-step Runge-Kutta scheme to maintain $\Delta t^{2}$ order accuracy [34]. The ions are propagated alongside the electrons in the Ehrenfest scheme, which is expected to be valid at these very short time scales. Because of the very small time step used in the real time propagation of electrons, the total simulation time was limited to 9.6 fs. When modeling an Auger decay occurring at $t=0$, we do not take into account the presence of a K-hole vacancy in the calculation of the valence MO (displayed in Figures 2a, 3a, 4a and 5a).

The analysis of the fragments charges were performed in the Bader scheme [35]. $\mathrm{CO}$ and $\mathrm{OH}$ bonds are considered broken, when the bond length is greater than 2.0 and $1.5 \AA$, respectively.

Supplementary Materials: The following are available online at http:/ /www.mdpi.com/2412-382X/3/4/24/s1, Figure S1: Radial Distribution Functions.

Author Contributions: Conceptualization, M.-A.H.d.P., M.-P.G., R.V., K.F., A.Y., and M.-F.P.; Formal analysis, M.-A.H.d.P., A.H., and M.-F.P.; Funding acquisition, M.-A.H.d.P. and A.Y.; Investigation, M.-A.H.d.P., A.H., and M.-F.P.; Writing—original draft, M.-A.H.d.P. and M.-F.P.; Writing—review \& editing, M.-P.G., R.V., K.F., and A.Y.

Funding: This research was funded by Électricité de France (grant number RB 2015-03) and by the Japan Atomic Energy Agency (Reimei Research Program). 
Acknowledgments: This work was performed using HPC resources from GENCI-CINES/IDRIS (grant number 2015-085014) and CCRE UPMC. All calculations were performed with the CPMD package, IBM Corp. 1990-2011, MPI für Festkörperforschung Stuttgart 1997-2001 (http:/ / www.cpmd.org). This work was partially supported by the Reimei Research Program (Japan Atomic Energy Agency) and EDF (grant number RB 2015-03).

Conflicts of Interest: The authors declare no conflicts of interest.

\section{Abbreviations}

The following abbreviations are used in this manuscript.

$\begin{array}{ll}\text { BLYP } & \text { Becke-Lee-Yang-Parr } \\ \text { BOMD } & \text { Born Oppenheimer molecular dynamics } \\ \text { CPMD } & \text { Car Parrinello molecular dynamics } \\ \text { HB } & \text { hydrogen bond } \\ \text { DFT } & \text { Density Functionnal Theory } \\ \text { MD } & \text { molecular dynamics } \\ \text { MO } & \text { molecular orbital } \\ \text { TDDFT } & \text { time-dependent DFT }\end{array}$

\section{References}

1. Chetioui, A.; Despiney, I.; Guiraud, L.; Adoui, L.; Sabatier, L.; Dutrillaux, B. Possible role of inner-shell ionization phenomena in cell inactivation by heavy ions. Int. J. Radiat. Biol. 1994, 65, 511-522. [CrossRef] [PubMed]

2. Boissière, A.; Champion, C.; Touati, A.; du Penhoat, M.A.H.; Sabatier, L.; Chatterjee, A.; Chetioui, A. DNA core ionization and cell inactivation. Radiat. Res. 2007, 167, 493-500. [CrossRef] [PubMed]

3. Emfietzoglou, D.; Papamichael, G.; Nikjoo, H. Monte Carlo Electron Track Structure Calculations in Liquid Water Using a New Model Dielectric Response Function. Radiat. Res. 2017, 188, 355-368, doi:10.1667/RR14705.1. [CrossRef] [PubMed]

4. Hervé du Penhoat, M.A.; Eschenbrenner, A.; Abel, F.; Boissière, A.; Guigner, J.M.; Chetioui, A.; Politis, M.F.; Touati, A.; Sage, E.; Jenner, T.J.; et al. Double-strand break induction and repair in V79-4 hamster cells: The role of core ionisations, as probed by ultrasoft X-rays. Int. J. Radiat. Biol. 2010, 86, 205-219, doi:10.3109/09553000903419296. [CrossRef] [PubMed]

5. Goodhead, D. Initial Events in the Cellular Effects of Ionizing Radiations: Clustered Damage in DNA. Int. J. Radiat. Biol. 1994, 65, 7-17, doi:10.1080/09553009414550021. [CrossRef] [PubMed]

6. Georgakilas, A.G.; O'Neill, P.; Stewart, R.D. Induction and Repair of Clustered DNA Lesions: What Do We Know So Far? Radiat. Res. 2013, 180, 100-109, doi:10.1667/RR3041.1. [CrossRef] [PubMed]

7. Ballarini, F.; Altieri, S.; Bortolussi, S.; Carante, M.; Giroletti, E.; Protti, N. The BIANCA model/code of radiation-induced cell death: Application to human cells exposed to different radiation types. Radiat. Environ. Biophys. 2014, 53, 525-533, doi:10.1007/s00411-014-0537-6. [CrossRef]

8. Carante, M.P.; Altieri, S.; Bortolussi, S.; Postuma, I.; Protti, N.; Ballarini, F. Modeling radiation-induced cell death: Role of different levels of DNA damage clustering. Radiat. Environ. Biophys. 2015, 54, 305-316, doi:10.1007/s00411-015-0601-x. [CrossRef]

9. Henke, B.; Gullikson, E.; Davis, J. X-Ray Interactions: Photoabsorption, Scattering, Transmission, and Reflection at $\mathrm{E}=50-30,000 \mathrm{eV}, \mathrm{Z}=1-92 . \quad$ At. Data Nucl. Data Tables 1993, 54, 181-342, doi:10.1006/adnd.1993.1013. [CrossRef]

10. Goodhead, D.T.; Thacker, J. Inactivation and Mutation of Cultured Mammalian Cells by Aluminium Characteristic Ultrasoft X-rays I. Properties of Aluminium X-rays and Preliminary Experiments with Chinese Hamster Cells. Int. J. Radiat. Biol. 1977, 31, 541-559, doi:10.1080/09553007714550651. [CrossRef]

11. Yokoya, A.; Ito, T. Photon-induced Auger effect in biological systems: a review. Int. J. Radiat. Biol. 2017, 93, 743-756, doi:10.1080/09553002.2017.1312670. [CrossRef] [PubMed]

12. Bolognesi, P.; Castrovilli, M.; O’Keeffe, P.; Casavola, A.; Catone, D.; Turchini, S.; Avaldi, L. Photofragmentation of organic molecules of biological interest: The pyrimidine and $2 \mathrm{Br}-\mathrm{pyrimidine}$ cases. Nucl. Instrum. Methods Phys. Res. Sect. B Beam Interact. Mater. Atoms 2012, 279, 118-123.10.1016/j.nimb.2011.10.063. [CrossRef] 
13. Ha, D.; Huels, M.; Huttula, M.; Urpelainen, S.; Kukk, E. Experimental and ab initio study of the photofragmentation of DNA and RNA sugars. Phys. Rev. A 2011, 84, 033419, doi:10.1103/PhysRevA.84.033419. [CrossRef]

14. López-Tarifa, P.; Gaigeot, M.P.; Vuilleumier, R.; Tavernelli, I.; Alcamí, M.; Martín, F.; Hervé du Penhoat, M.A.; Politis, M.F. Ultrafast Damage Following Radiation-Induced Oxidation of Uracil in Aqueous Solution. Angew. Chem. Int. Ed. 2013, 52, 3160-3163, doi:10.1002/anie.201208038. [CrossRef] [PubMed]

15. Odelius, M. Molecular dynamics simulations of fine structure in oxygen K-edge X-ray emission spectra of liquid water and ice. Phys. Rev. B 2009, 79, 144204-144209, doi:10.1103/PhysRevB.79.144204. [CrossRef]

16. Stia, C.R.; Gaigeot, M.P.; Vuilleumier, R.; Fojón, A.O.; Hervé du Penhoat, M.A.; Politis, M.F. Theoretical investigation of the ultrafast dissociation of core-ionized water and uracil molecules immersed in liquid water. Eur. Phys. J. D At. Mol. Opt. Plasma Phys. 2010, 60, 77-83. [CrossRef]

17. Fujii, K.; Izumi, Y.; Narita, A.; Ghose, K.K.; López-Tarifa, P.; Touati, A.; Spezia, R.; Vuilleumier, R.; Gaigeot, M.P.; Politis, M.F.; et al. Roles of Hydration for Inducing Decomposition of 2-Deoxy-d-ribose by Ionization of Oxygen K-Shell Electrons. Radiat. Res. 2018, 189, 264-272, doi:10.1667/RR14225.1. [CrossRef]

18. Tavernelli, I.; Gaigeot, M.P.; Vuilleumier, R.; Stia, C.; Hervé du Penhoat, M.A.; Politis, M.F. Time-Dependent Density Functional Theory Molecular Dynamics Simulations of Liquid Water Radiolysis. ChemPhysChem 2008, 9, 2099-2103. [CrossRef]

19. Hervé du Penhoat, M.A.; Rodríguez Moraga, N.; Gaigeot, M.P.; Vuilleumier, R.; Tavernelli, I.; Politis, M.F. Proton Collision on Deoxyribose Originating from Doubly Ionized Water Molecule Dissociation. J. Phys. Chem. A 2018, 122, 5311-5320, doi:10.1021/acs.jpca.8b04787. [CrossRef]

20. Hervé du Penhoat, M.A.; Kamol Ghose, K.; Gaigeot, M.P.; Vuilleumier, R.; Fujii, K.; Yokoya, A.; Politis, M.F. Investigation of the fragmentation of core-ionised deoxyribose: A study as a function of the tautomeric form. Phys. Chem. Chem. Phys. 2015, 17, 32375-32383, doi:10.1039/C5CP05196G. [CrossRef]

21. Prendergast, D.; Galli, G. X-Ray Absorption Spectra of Water from First Principles Calculations. Phys. Rev. Lett. 2006, 96, 215502, doi:10.1103/PhysRevLett.96.215502. [CrossRef] [PubMed]

22. Campbell, J.; Papp, T. Widths of the atomic K-N7 levels. At. Data Nucl. Data Tables 2001, 77, 1-56, doi:10.1006/adnd.2000.0848. [CrossRef]

23. Miron, C.; Simon, M.; Leclercq, N.; Hansen, D.L.; Morin, P. Site-Selective Photochemistry of Core Excited Molecules: Role of the Internal Energy. Phys. Rev. Lett. 1998, 81, 4104-4107, doi:10.1103/PhysRevLett.81.4104. [CrossRef]

24. Inhester, L.; Oostenrijk, B.; Patanen, M.; Kokkonen, E.; Southworth, S.H.; Bostedt, C.; Travnikova, O.; Marchenko, T.; Son, S.K.; Santra, R.; et al. Chemical Understanding of the Limited Site-Specificity in Molecular Inner-Shell Photofragmentation. J. Phys. Chem. Lett. 2018, 9, 1156-1163, doi:10.1021/acs.jpclett.7b03235. [CrossRef]

25. Kukk, E.; Ha, D.T.; Wang, Y.; Piekarski, D.G.; Diaz-Tendero, S.; Kooser, K.; Itälä, E.; Levola, H.; Alcamí, M.; Rachlew, E.; et al. Internal energy dependence in x-ray-induced molecular fragmentation: An experimental and theoretical study of thiophene. Phys. Rev. A 2015, 91, 043417, doi:10.1103/PhysRevA.91.043417. [CrossRef]

26. Car, R.; Parrinello, M. Unified Approach for Molecular Dynamics and Density-Functional Theory. Phys. Rev. Lett. 1985, 55, 2471-2474, doi:10.1103/PhysRevLett.55.2471. [CrossRef]

27. Troullier, N.; Martins, J. Efficient pseudopotentials for plane-wave calculations. Phys. Rev. B 1991, 43, 1993-2006, doi:10.1103/PhysRevB.43.1993. [CrossRef]

28. Becke, A.D. Density-functional exchange-energy approximation with correct asymptotic behavior. Phys. Rev. A 1988, 38, 3098-3100, doi:10.1103/PhysRevA.38.3098. [CrossRef]

29. Lee, C.; Yang, W.; Parr, R. Development of the Colle-Salvetti correlation-energy formula into a functional of the electron density. Phys. Rev. B 1988, 37, 785-789, doi:10.1103/PhysRevB.37.785. [CrossRef]

30. Marzari, N.; Vanderbilt, D. Maximally localized generalized Wannier functions for composite energy bands. Phys. Rev. B 1997, 56, 12847-12865, doi:10.1103/PhysRevB.56.12847. [CrossRef]

31. Hunt, P.; Sprik, M.; Vuilleumier, R. Thermal versus electronic broadening in the density of states of liquid water. Chem. Phys. Lett. 2003, 376, 68-74, doi:10.1016/S0009-2614(03)00954-0. [CrossRef]

32. Tavernelli, I.; Röhrig, U.F.; Rothlisberger, U. Molecular dynamics in electronically excited states using time-dependent density functional theory. Mol. Phys. 2005, 103, 963-981, doi:10.1080/00268970512331339378. [CrossRef] 
33. Tavernelli, I. Electronic density response of liquid water using time-dependent density functional theory. Phys. Rev. B 2006, 73, 094204. [CrossRef]

34. Theilhaber, J. Ab initio simulations of sodium using time-dependent density-functional theory. Phys. Rev. B 1992, 46, 12990-13003, doi:10.1103/PhysRevB.46.12990. [CrossRef] [PubMed]

35. Bader, R.F.W. Atoms in Molecules—A Quantum Theory; Oxford University Press: Oxford, UK, 1990.

(C) 2019 by the authors. Licensee MDPI, Basel, Switzerland. This article is an open access article distributed under the terms and conditions of the Creative Commons Attribution (CC BY) license (http:/ / creativecommons.org/licenses/by/4.0/). 